\title{
Characterization of Eudragit types and Kollidon SR inter-polymer complexes and their effects on the drug release
}

\author{
Syaiful Choiri ${ }^{1 *}$, Teuku Nanda Saifullah Sulaiman ${ }^{2 *}$, Abdul Rohman ${ }^{3}$ \\ ${ }^{1}$ Pharmaceutical Technology and Drug Delivery, Pharmaceutics Research Group, Department of Pharmacy, Universitas Sebelas Maret, Surakarta, Indonesia. \\ ${ }^{2}$ Department of Pharmaceutics, Universitas Gadjah Mada, Yogyakarta, Indonesia. \\ ${ }^{3}$ Department of Pharmaceutical Chemistry, Universitas Gadjah Mada, Yogyakarta, Indonesia.
}

\section{ARTICLE INFO \\ Received on: $22 / 01 / 2019$ \\ Accepted on: 20/05/2019 \\ Available online: 01/07/2019}

\section{Key words:}

Eudragit, Kollidon SR, inter-polymer complex, drug release.

\begin{abstract}
A novel of polymer combination promotes an increase of the ability for controlling the drug release. The objective of this research was to characterize the inter-polymer complexes (IPCs) of Eudragit (Eud) types (Eud RS, Eud L, or Eud E) and Kollidon SR (KSR), and elucidate their effects on the drug release kinetics and mechanism. Different preparation techniques were proposed using spray drying and ultrasonic-assisted anti-solvent techniques. The thermal activity, e.g., glass transition temperature $\left(T_{\mathrm{g}}\right)$ and Fourier transform infrared spectroscopy were used to characterize the molecular interaction of these IPCs. Theophylline (THP) was selected as a drug model. The effect on the drug release kinetics and mechanism was the main concern of this study. Depending on the results, the hydrogen bonding formation between polymers was observed by a shifting of $\mathrm{OH}$ and carbonyl group vibrations. In addition, the van der Waals interaction was identified by an alteration in the vibrational band around the $1,000-1,500 \mathrm{~cm}^{-1}$. Meanwhile, the change of physicochemical characteristic was identified by the $T_{\mathrm{g}}$ of IPCs. Eud E-KSR and Eud E-Eud L IPC were unable to control the THP release. Meanwhile, Eud L-KSR IPC and Eud RS-KSR IPC were success to control the THP release, but it was $\mathrm{pH}$ dependent and independent, respectively. This study concluded that the IPCs allowed the THP release in a controlled manner based on the IPC characteristics and their interactions. Either positive or negative interactions on the drug release were observed due to native characteristics of polymers.
\end{abstract}

\section{INTRODUCTION}

Polymer is widely used to control drug release, especially on an oral controlled release delivery (Ainurofiq and Choiri, 2015; Borgquist et al., 2006; Liechty et al., 2010). The selection of an appropriate polymer or combination of polymers is a fundamental step to determine the performance of the controlled release dosage form (Merkle, 2015). Physicochemical and physicomechanical characteristics of the polymers are the most important factors that determine the ability to control the drug release (Liechty

\section{*Corresponding Authors}

Syaiful Choiri, Pharmaceutical Technology and Drug Delivery, Pharmaceutics Research Group, Department of Pharmacy, Universitas Sebelas Maret, Surakarta, Indonesia.E-mail: syaiful.apt @ gmail.com Teuku Nanda Saifullah Sulaiman, Department of Pharmaceutics, Universitas Gadjah Mada, Yogyakarta, Indonesia.

E-mail:tn_saifullah@ugm.ac.id et al., 2010; Robertis et al., 2015). As renaissance, a polymer was modified chemically (Masina et al., 2017; Zayed et al., 2017) or physically (Hong et al., 2016) and blended with an appropriate polymer combination to obtain desired characteristics either physicochemical or physicomechanical properties for controlling the drug release. A novel polymer combination was applied for controlling the drug release by matrix system (Kubova et al., 2017). Drugs are usually incorporated into polymers in the oral controlled release formulations through either physical mixture as a matrix or amorphous solid dispersion (Ali et al., 2017; Ohyagi et al., 2017; Park et al., 2008). High-dose loading and freely watersoluble drugs have some hurdles to be formulated, especially in the oral controlled release formulation. In addition, the dosage form becomes bulky and non-acceptable due to its big size (Qiu and Lee, 2017), and the burst release is observed due to an inadequate drug release control capacity of polymer (Huang and Brazel, 2001). To overcome these limitations, insoluble-swellable polymers would be incorporated in the polymeric blending to enhance the ability 
of polymer to control the drug release through interaction between polymers. The interaction of insoluble and swellable polymers induces the physical barrier of drug release and enhances the matrix diffusion resistance. Therefore, the interaction of both polymers can maintain the ability to control the drug release, even though the amount of total polymers is reduced compared to the single polymer system (Kubova et al., 2017).

Inter-polymer complex (IPC) is an intermolecular interaction between two polymers which is able to alter the physicochemical and physicomechanical properties of the polymers (Jeganathan and Prakya, 2015; Robertis et al., 2015; Terashima et al., 2015). This interaction involves hydrogen bonding, ionic, or van der Waals interactions. Either positive or negative effects are possible to be obtained depending on its interaction (Khutoryanskaya et al., 2014; Khutoryanskiy, 2007; Robertis et al., 2015). Several IPCs have been reported that it could be used to control the drug release, e.g., copovidone and Carbopol (Zhang et al., 2017), Polyox and Carbopol (Zhang et al., 2016a), polyethylene oxide and poly acrylic acid (Zhang et al., 2016b), and inter polyelectrolyte complexes using several polymers, such as Eudragit E, Eudragit L, hydroxyl propyl methyl cellulose (HPMC) succinic acid, chitosan, and poly acrylic acid (Jeganathan and Prakya, 2015; Moustafine et al., 2012; Moustafine and Bobyleva, 2006; Mustafin, 2011; Park et al., 2008). However, until to the date, there was no reported data about the characterization of IPC between poly-methacrylate copolymer [Eudragit types (Eudragit RS, L, and E)] and copolymer poly-vinyl acetate-copovidon (Kollidon SR) and their effects on the drug release.

Poly-methacrylate copolymer (Eudragit; Eud) is a unique polymer and produces different characteristics depending on the substitution as a $\mathrm{pH}$ dependent polymer (Patra et al., 2017). Usually, it uses to modify the drug release for delayed release formulation (Eud L), protecting from an ambient condition or taste masking (Eud E), or as a material for sustained release formulation (Eud RS/ Eud RL) (Elzayat et al., 2017; Thakral et al., 2013). Blending of Eud RS and KSR in the film coating of HPMC matrix tablet enhanced the mechanical robustness of HPMC. This polymer can interact with other polymers in blending, especially in unconventional blending of Eudragit RS with KSR (Ali et al., 2017). Theoretically, several mechanisms in the interaction between polymers can be involved, i.e., hydrogen bonding with Eud L, Van der Waals interaction with Eud E or Eud RS. Meanwhile, the IPC based on ionic interaction/inter-polyelectrolyte, i.e., Eud E-Eud L basically can alter the physicochemical and physicomechanical properties (Khutoryanskiy, 2007; Robertis et al., 2015). The physicochemical and physicomechanical characteristics of IPC depended on the native characteristic and its interaction. Hence, the purpose of this study was to characterize the IPC of several Eud types, such as Eud RS, Eud L, and Eud E, with KSR and elucidate their effects on the drug release. In this study, Theophylline, THP, was selected as a drug model. THP has solubility in water of $8.3 \mathrm{mg} / \mathrm{ml}$, and according to the functional group, it includes in weak acid drug which has $\mathrm{pKa}$ value of 8.6. Due to this characteristic, it has a negligible effect on solubility in range $\mathrm{pH}$ of 1.2-6.8. Therefore, for intended use, this drug has no $\mathrm{pH}$ effect on drug release during pH shifting (Zhang et al., 2017). As pharmacological perspective, THP is applied for asthma treatment and it has a narrow therapeutic window which controlled release formulation is suitable to address this issue due to avoiding fluctuation of drug concentration. Thereafter, it provides better clinical outcome than an immediate release formulation (Hayashi et al., 2005; Makino et al., 2006).

\section{MATERIALS AND METHODS}

\section{Material}

Eudragit RS, Eudragit E, and Eudragit L were obtained from Evonik (Darmstadt, Germany) as gift samples and Kollidon SR was obtained from BASF (Ludwigshafen, Germany) as a gift sample. THP (CSPC Innovation Pharmaceutical Co. Ltd., China) was purchased from a local supplier.

\section{Preparation of Eudragit RS and Kollidon SR inter-polymer complex}

All IPCs were prepared in an equal weight ratio, and Eudragit polymers and KSR were dissolved in methanol and acetone ( $20 \% \mathrm{w} / \mathrm{v}$ solid loading), respectively. KSR solution was added to Eud RS solution at rate of $10 \mathrm{ml} /$ minute and stirred for 24 hours. The solution mixture was solidified using several techniques.

Spray drying (SD) technique was applied to solidify the IPC Eud RS-KSR, Eud L-KSR, Eud E-KSR. Briefly, spray drying process was performed using a Buchi mini spray dryer B-290 (Flawil, Switzerland) by feeding rate of $5 \mathrm{ml} /$ minute, nozzle size of $2.0 \mathrm{~mm}$, atomization of $2.5 \mathrm{bar}$, inlet and outlet temperatures of $50^{\circ} \mathrm{C}$ and $30^{\circ} \mathrm{C}$, respectively.

On the other hand, different technique to solidify the polymer solution was carried out, an ultrasonic assisted anti-solvent (AS) technique was applied for IPC Eud RS-KSR and Eud L-KSR. Briefly, the solution mixture of Eud RS-KSR was added to the water as an anti-solvent in the ultrasonic bath (Branson 2800 ultrasonic bath; Danbury, CT) at a constant rate of $10 \mathrm{ml} /$ minutes. Furthermore, the solution was stirred and centrifuged $(6,000 \times g$ for 15 minutes $)$ using a Thermo ST-16 centrifuge (Waltham, MA), the sediment was collected and dried using oven (Memmert; Schwabach, Germany) at $40^{\circ} \mathrm{C}$ for 24 hours and freeze drying using a Thermo Power Dry LL1500 freeze dryer (Waltham, MA) at $-60^{\circ} \mathrm{C}$ and $50 \mathrm{mBar}$ for IPC Eud L-KSR and Eud RS-KSR, respectively.

EudE-Eud L IPC could be obtained by different method, i.e., solvent evaporation (SE). Eud E and Eud L were separately dissolved in methanol. Eud E solution was added to the Eud L solution under stirring condition for 24 hours. The sediment was collected and dried using an oven (Memmert; Schwabach, Germany) at temperature of $40^{\circ} \mathrm{C}$ for 24 hours. All the solidified IPCs were passed through 250 $\mu \mathrm{m}$ sieve and stored in a desiccator until further analysis.

\section{Differential scanning calorimetry (DSC)}

Thermal behavior of the polymers and IPCs was characterized using a Shimadzu DSC-60 differential scanning calorimeter (Kyoto, Japan). An approximate of $10 \mathrm{mg}$ sample was placed into an $\mathrm{Al}_{2} \mathrm{O}_{3}$ pan and heated from $30^{\circ} \mathrm{C}$ to $200^{\circ} \mathrm{C}$ at a rate of $10^{\circ} \mathrm{C} /$ minute under a $30 \mathrm{ml} /$ minute nitrogen atmosphere. An empty pan was used as a reference.

\section{Fourier transform infrared (FTIR) spectroscopy}

Vibrational spectrum of the polymers and IPCs was analyzed using Thermo Nicolet i50 FTIR spectrometer (Waltham, 
MA). The FTIR was utilized using attenuate total reflectance (ATR) with $\mathrm{ZnSe}$ crystal and deuterated triglycine sulphate detector. Sample was placed on the ATR crystal and scanned from 650 to $4,000 \mathrm{~cm}^{-1}$ with a resolution of $2 \mathrm{~cm}^{-1}$ and 32 times iteration.

\section{Tablet preparation}

Tablet was prepared using a direct compression technique. THP load of $50 \%$ was used and $50 \%$ polymer was incorporated. THP and either IPC or physical mixture were mixed using cube mixer (Erweka KB; Langen, Germany) at $40 \mathrm{rpm}$ for 15 minutes. The magnesium stearate $1 \%$ was added to the mixture and mixed at $40 \mathrm{rpm}$ for 3 minutes. The tablet was manually weighted at $400 \mathrm{mg}$ and pressed using Korsch single punch tablet machine (Berlin, Germany) with flat-faced punch diameter of 10 $\mathrm{mm}$ and tablet's crushing strength was controlled at $60 \pm 5 \mathrm{~N}$ to avoid the effect of the tablet crushing strength on the THP release.

\section{Drug release characterization}

Drug release was characterized using Erweka DT820 dissolution tester (Heusenstamm, Germany). Drug release characterization was carried out for 6 hours under an alteration of $\mathrm{pH}$ value from 1.2 to 6.8 . First, a $500 \mathrm{ml}$ of hydrochloric acid $0.1 \mathrm{M} \mathrm{(pH}$ 1.2) was used as medium during the first 3 hours testing. Samples were taken at 5, 15, 30, 60, 90, 120, and 180 minutes. Furthermore, to change the $\mathrm{pH}$ value, a $500 \mathrm{ml}$ of dipotassium hydrogen phosphate $0.14 \mathrm{M}$ was added gently at a rate of $50 \mathrm{ml} /$ minutes. Samples were withdrawn at 210, 240, 300, and 360 minutes. All the samples were analyzed spectrophotometrically at a wavelength of $270 \mathrm{~nm}$ using a Shimadzu U-2900 spectrophotometer (Tokyo, Japan). The THP release profiles were compared statistically depending on the both of dissolution efficiency (DE) (Eq. 1) in the medium of $\mathrm{pH} 1.2$ and pH 6.8 and similarity factor $\left(f_{2}\right)$ (Eq. 2) using following equations (Costa and Sousa Lobo, 2001).

$$
\begin{aligned}
& \mathrm{DE}=\frac{\int_{0}^{t} y \delta t}{100 T} \times 100 \% \\
& f_{2}=50 \log 1+\left(\frac{1}{n}\right) \sum_{t=1}^{n}\left(R_{t}-T_{t}\right)^{2} \times 100
\end{aligned}
$$

where $y$ is amount of THP released in time $t$ and $T$ is total time. The DE was calculated during THP released at $\mathrm{pH} 1.2\left(\mathrm{DE}_{\mathrm{pH} 1.2}\right), \mathrm{pH}$ $6.8\left(\mathrm{DE}_{\mathrm{pH} 6.8}\right)$, and during 360 minutes $\left(\mathrm{DE}_{\mathrm{total}}\right)$. In the $f_{2}$ equation, $n$ is the number of time points, $R_{t}$ denotes percentage of the THP release of the reference (PM) at time $t$, and $T_{t}$ denotes percentage of the THP release of the test condition (IPC) at time $t$. In order to distinguish the THP release depending on theirs multifactor of multiple sampling times, score plot of multivariate analysis using principal component analysis (PCA) was implemented.

The THP release of IPCs was modeled using Higuchi (Eq. 3) and Korsmeyer Pepas equation (Eq. 4), first-order kinetic (Eq. 5) and exponential (Eq. 6) or polynomial (Eq. 7) equations.

$$
\begin{aligned}
& Q t=k_{H} * t^{1 / 2} \\
& Q t=k * t^{n}
\end{aligned}
$$

$$
\begin{aligned}
& Q t=100 \exp \left(-k_{1} * \mathrm{t}\right) \\
& Q t=a *\left(1-\exp \left(-b^{*} \mathrm{t}\right)+c *(1-\exp (-d * \mathrm{t}))\right.
\end{aligned}
$$

or

$$
Q t=y_{0}+a t^{3}+b t^{2}+c^{t}
$$

where $Q t$ is the amount of THP released, $t$ is time, $k_{H}$ as Higuchi constant, $k$ as diffusional constant of Korsmeyer-Peppas equation, $n$ as diffusional exponent, $k_{1}$ as diffusional constant of first order kinetics, and $a, b, c$, and $d$ were regression coefficients from double exponential and quadratic models.

\section{RESULTS AND DISCUSSION}

In order to characterize the interaction of polymer blending and intermolecular polymer interactions, IPCs of KSREud types were prepared. Eud types have different substitutions, thus it has different characteristics, e.g., $\mathrm{pH}$ dependent and solubility (Patra et al., 2017; Thakral et al., 2013). Theoretically, the interaction between Eud types and KSR has different interactions depending on the type of Eud. Combination of Eud RS or Eud E and KSR interacts through a Van der Waals interaction. Meanwhile, Eud L and KSR have a hydrogen bonding interaction. An ionic interaction was observed between Eud E and Eud L. The Eud RS-KSR IPC was prepared by SD and AS followed by drying in the oven. However, the AS method was not applicable due to low $T_{\mathrm{g}}$ and film forming temperature of Eud RS. This reason was similar to the Eud E-KSR IPC. Furthermore, these IPCs using AS did not use in the study of THP release. In addition, the interaction between Eud $\mathrm{E}$ and Eud L was observed spontaneously by formation of precipitation when Eud E added to Eud L solution without a further treatment, thus precipitation was collected and dried. Furthermore, to elucidate their molecular interactions between two polymers, further characterizations, e.g., vibrational spectroscopy and thermal analysis were performed.

The molecular interaction of polymer blending was carried out using ATR-FTIR. Moreover, the physical mixture of the polymers was prepared under similar ratio to the IPC, thus shifting of vibrational peak and reducing its intensity could be used to identify the interaction between polymers (Riaz and Ashraf, 2014). FTIR spectra of Eud RS, KSR, and PM, IPC Eud RS-KSR are presented in Figure 1a. The result showed that an interaction was detected and highlighted by a dashed red line. The carbonyl esters of KSR were 1,729.89 and 1,655.82 $\mathrm{cm}^{-1}$ and the $\mathrm{C}-\mathrm{O}$ vibration was found at $1,226.27 \mathrm{~cm}^{-1}$, while the carbonyl and C-O vibrations of Eud RS were 1,722.55 and 1,143.01 $\mathrm{cm}^{-1}$, respectively. Furthermore, the PM of both polymers imitated both of two bands and patterns of native spectra. Although, an interaction was observed by shifting of carbonyl ester of KSR and $\mathrm{C}-\mathrm{O}$ vibrations. In order to elucidate the molecular interaction between polymers, polymer mixture (PM) spectrum was applied and used to compare the different preparation methods. Despite similar weight ratio between IPC and PM, the interaction of both polymers was observed by the shifting of specific peak vibrations as well as the intensity changes. The interaction was overviewed by differential spectra between IPCs and PM (Fig. 1b). The differential spectra measured an alteration of both intensity and 
peak shifting. The differential spectrum was calculated based on the distance of absorbance between PM and IPC. The down signal of peak indicated the absorbance of IPC higher than that of PM. Moreover, the upward signal of peak indicated the absorbance of IPC lower than that of PM. The significant shifting of vibrational peak could be observed by a sharp peak on the differential spectra. Dissimilar pattern of differential spectra of SD-PM and AS-PM showed that different preparation methods promoted different interactions of both polymers. However, the FTIR band of two IPCs had a similar pattern, thus we assumed that the interaction only affected on the quantity of molecular interactions.

Depending on the molecular structure of Eud L and KSR, the possible interaction occurred through a hydrogen bonding interaction. FTIR spectra of Eud L-KSR IPC are presented in Figure 1c. The interaction was highlighted by a dashed red line around 1,000 $1,750 \mathrm{~cm}^{-1}$ and $3,000-3,500 \mathrm{~cm}^{-1}$. Shifting of the $\mathrm{C}=\mathrm{O}$ vibrations of Eud L and KSR and the $\mathrm{OH}$ vibration of Eud L confirmed the interaction. The spectra difference between two IPCs under different preparation techniques showed a similar pattern and intensity (Fig. 1d). Hence, the preparation technique did not affect the interaction. Due to similar substitution characteristic of the side chain of Eud E to Eud RS, the possible interaction was similar too. The FTIR spectra of Eud E-KSR IPC are presented in Figure 2a. There was no major interaction although the interaction was highlighted around 1,000 $1,500 \mathrm{~cm}^{-1}$ and $1,700-1,750 \mathrm{~cm}^{-1}$ (Fig. 2b) and it was possible to van der Waals interaction. Alteration of the intensity of IPC was observed by reducing its intensity compared to the PM intensity.

Inter-polyelectrolyte interaction was observed in the Eud E-Eud L IPC. Eud E as a polycationic polymer and Eud L as a polyanionic polymer interacted by proton transfer of this system. The interaction could be observed in the FTIR spectra of Eud E-Eud L IPC SE (Fig. 2c). The interaction was dominantly occurred by an alteration of $\mathrm{C}-\mathrm{O}$ vibration due to a proton transfer between two polymers (Jeganathan and Prakya, 2015). The interaction was showed by a sharp down peak at the spectra difference between PM and IPC SE (Fig. 2d).

In addition, to confirm the interaction of IPCs, the thermal analysis using DSC was carried out. The glass transition $\left(T_{\mathrm{g}}\right)$ was characterized as a main phenomenon in the polymer softening. The miscible polymer shows a single $T_{\mathrm{a}}$ although an immiscible polymer retains $T_{\mathrm{g}}$ of each polymer, and the $T_{\mathrm{g}}$ value has an ideal blend function depending on its fraction (Brostow
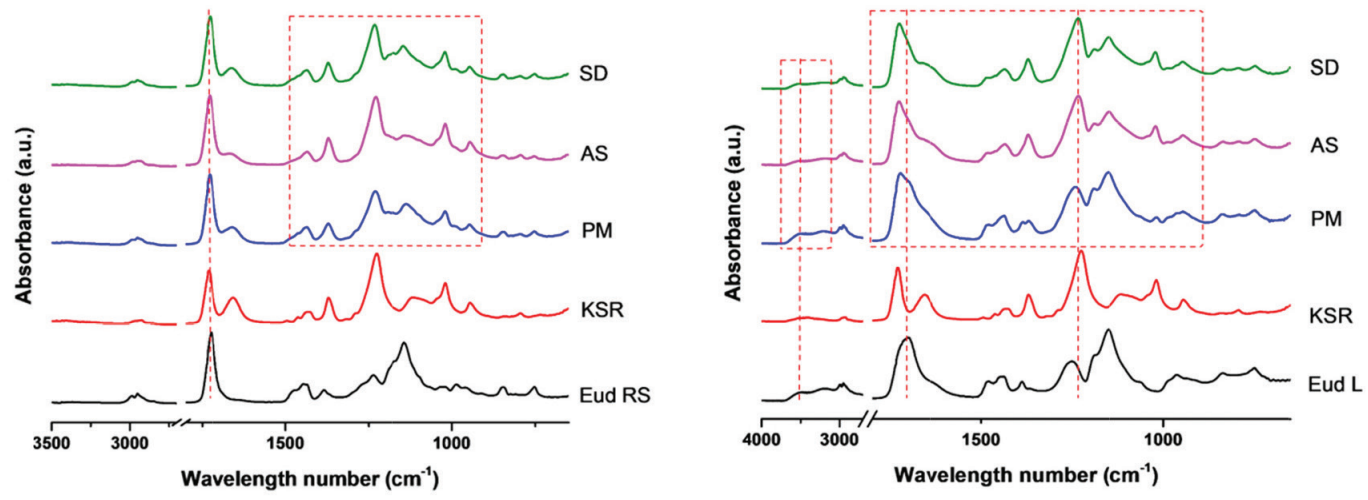

a
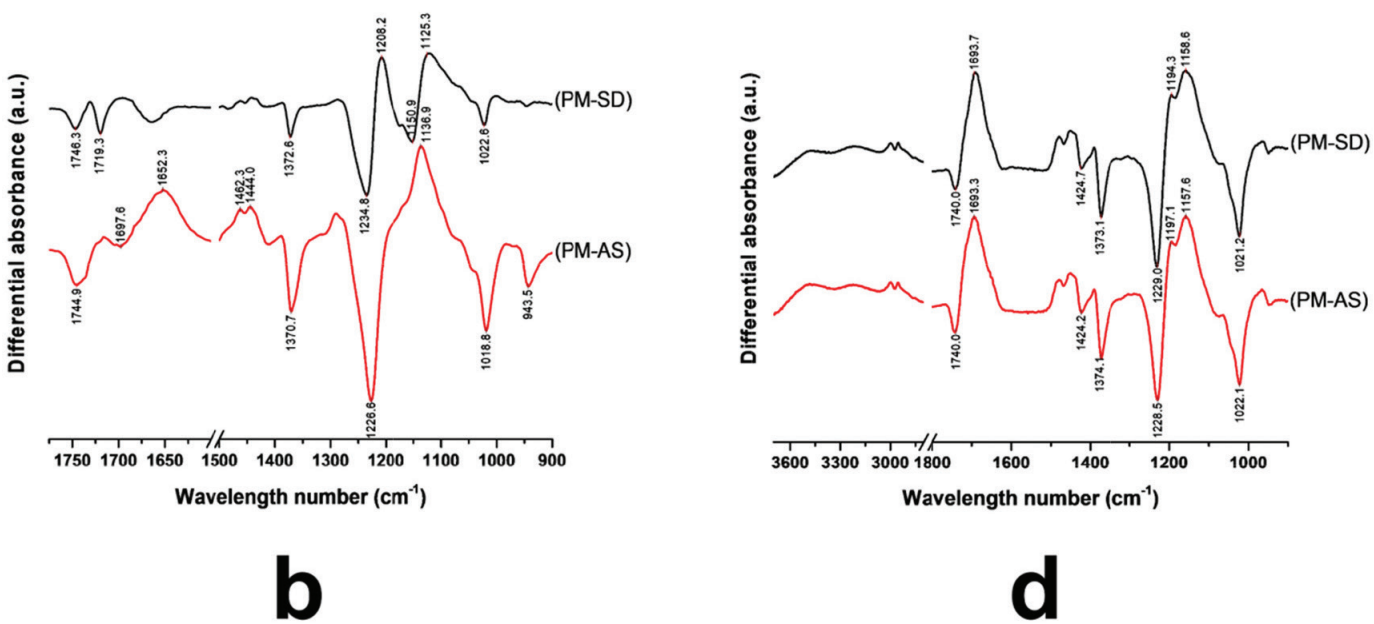

Figure 1. (a) FTIR Spectra of Eudragit RS (Eud RS)-Kollidon SR (KSR) inter-polymer complexes (IPCs); (b) differential spectra PM and Eud RS-KSR IPC; (c) Eud L-KSR IPC; and (d) differential spectra of PM and Eud L-KSR IPC. Physical mixture (PM) and inter-polymer complexes using spray drying (SD) and anti-solvent (AS) techniques. 
et al., 2008). The DSC thermograms of IPCs are presented in Figure 3. The PM of Eud RS-KSR showed two $T_{\mathrm{g}} \mathrm{s}$, the $\mathrm{KSR}\left(33.70^{\circ} \mathrm{C}\right)$ and Eud RS $\left(53.09^{\circ} \mathrm{C}\right)$ (Fig. 3a), respectively. As previous reports, the $T_{\mathrm{g}}$ of KSR and Eud RS was $42.54^{\circ} \mathrm{C}$ (Saerens et al., 2012) and $61^{\circ} \mathrm{C}-63^{\circ} \mathrm{C}$ (Khodaverdi et al., 2012; Zhu et al., 2002), respectively. The $T$ of KSR strongly depended on the relative humidity ( $\mathrm{RH})$, $T$ at $32^{\circ} \mathrm{C}$ was observed at $75 \% \mathrm{RH}$ and $48^{\circ} \mathrm{C}$ was observed at $0 \%$ RH (Hauschild and Picker-Freyer, 2006). Eud RS-KSR showed the most complete and miscible among the IPCs. The $T_{\mathrm{g}}$ of native polymers, e.g., Eud RS and KSR was disappeared and the polymer softening followed the degradation was observed at $184.28^{\circ} \mathrm{C}$. On the Eud L-KSR IPC, a broad endothermic peak was observed due to a curing effect. This effect increased the interaction between polymers. In the film coating, the curing effect was applied to enhance robustness of film layer and stability due to enhancement of degree of crosslinked polymer (Gendre et al., 2012). This phenomenon was also observed in the Eud E-Eud L IPC. The thermogram of Eud L-KSR IPC (Fig. 3b) confirmed the interaction through a hydrogen bonding due to the shifting to the higher $T_{\mathrm{g}}$ value both of Eud L $T_{\mathrm{g}}\left(136.99^{\circ} \mathrm{C}\right)$ and $\mathrm{KSR} T_{\mathrm{g}}\left(55.57^{\circ} \mathrm{C}\right)$ from the Eud L $T_{g}\left(133.05^{\circ} \mathrm{C}\right)$ and KSR $T_{g}\left(34.56^{\circ} \mathrm{C}\right)$. Although, in the PM of Eud L-KSR appeared a new one $T_{\mathrm{g}}$ at $55.26^{\circ} \mathrm{C}$, while the KSR and
Eud L $T_{\mathrm{g}} \mathrm{s}$ were observed at $36.43^{\circ} \mathrm{C}$ and $130.93^{\circ} \mathrm{C}$, respectively. Previous studies reported that $T_{\mathrm{g}}$ of Eud L was $123^{\circ} \mathrm{C}-124^{\circ} \mathrm{C}$ (Lang et al., 2016; Moustafine et al., 2006). Because of the $T_{\mathrm{g}}$ shifting, it could be observed that an interaction shifted the $T_{\mathrm{g}}$ value either in the PM or IPC. Although, the IPCs had significant interaction compared to the PM. Interaction of Eud E-KSR IPC (Fig. 3c) was observed due to $T_{\mathrm{g}}$ shifting to the higher $T_{\mathrm{g}}$ value from $34.56^{\circ} \mathrm{C}$ to $38.03^{\circ} \mathrm{C}$. Significant change of thermogram was observed in Eud E-Eud L IPC (Fig. 3d) revealed by new broadening of endothermic peak and $T_{\mathrm{g}}$ of $107.83^{\circ} \mathrm{C}$ due to the curing effect.

All $T_{\mathrm{g}} \mathrm{s}$ of the IPCs are resumed in Table 2. Depending on the native $T_{\mathrm{g}}^{\mathrm{g}}$ of each polymer, we could calculate the predicted value of $T_{\mathrm{g}}$ based on a Gordon-Taylor equation (1952) which derived from Wood ( 1958).

$$
T_{g \text { pred }}=\frac{T_{g 1} \times w_{1} \times C_{p 1}+T_{g 2} \times w_{2} \times C_{p 2}}{w_{1} \times C_{p 1}+w_{2} \times C_{p 2}}
$$

In which $T_{\mathrm{g} 1}$ and $T_{\mathrm{g} 2}$ are the glass transition of polymer 1 and polymer 2, e.g., Eud RS-KSR IPC the $T_{\mathrm{g} 1}$ and $T_{\mathrm{g} 2}$ are $T_{\mathrm{g}}$ of Eud $\mathrm{RS}$ and KSR, respectively. The $w$ is the weight fraction of polymer and $\triangle C p$ is the specific heat change. Depending on the predicted
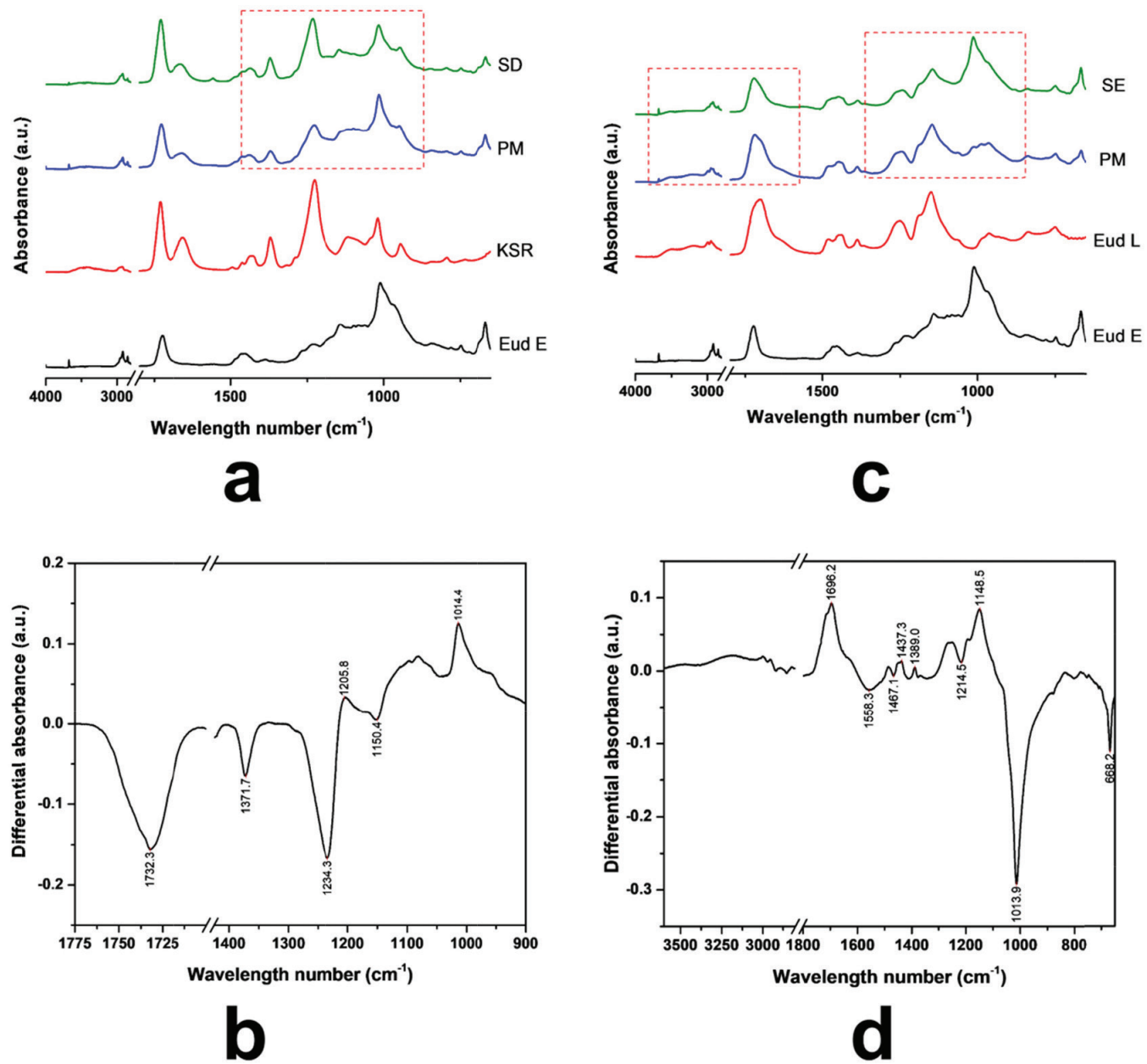

Figure 2. (a) FTIR Spectra of Eudragit E (Eud E)-Kollidon SR (KSR) inter-polymer complexes (IPCs); (b) differential spectra of PM and Eud E-KSR IPC; (c) Eud E-Eud L IPC; and (d) differential spectra of PM and Eud E-Eud L IPC. Physical mixture (PM) and inter-polymer complexes using spray drying (SD) and solvent evaporation (SE) techniques. 
$T_{\mathrm{g}}$ (Table 1), there was only experimental $T_{\mathrm{g}}$ of Eud E-KSR closed to the predicted $T_{\mathrm{g}}$. The predicted $T_{\mathrm{g}}$ was calculated based on the ideal mixture of the polymer. Furthermore, the interaction between polymers which altered to be non-ideal mixture/ polymer complexes had a long distance between the predicted and experimental values. Generally, IPC had to shift the $T_{\mathrm{g}}$ to the higher value. The interaction between polymer which formed IPC indirectly promoted the lengthen of the polymer chain, thus the $T_{\mathrm{g}}$ increased (Brostow et al., 2008).

To elucidate the effect of inter-polymer complexes on the THP release, we performed dissolution testing for $50 \%$ of THP loading. The THP release of Eud RS-KSR IPCs and its PM is presented in Figure 4a. The THP release of Eud RS-KSR IPCs and PM had a similar pattern in term of THP release in the $\mathrm{pH} 1.2$ and $6.8\left(f_{2}=77.87\right)$. In other word, there were no significant changes of THP release rate during the $\mathrm{pH}$ shifting. Therefore, the interaction between both polymers had a $\mathrm{pH}$-independent characteristic. IPC did not alter its ability, but it improved the ability to retard the THP release. Depending on the DE results in $\mathrm{pH} 1.2, \mathrm{pH} 6.8$, the THP release of PM had higher than that of IPC. Both Eud RS and KSR are water-insoluble polymer but swellable polymer. The ability to control the THP release based on the THP permeability (Hauschild and Picker-Freyer, 2006; Khodaverdi et al., 2012). Thus, we assumed that the IPC promoted the interaction between Eud RS and KSR and produced more impermeable polymer due to alteration the chain mobility of polymer.

The THP releases of Eud L-KSR IPC and PM are presented in Figure 4b. The THP releases between Eud L-KSR IPC and PM had a different pattern, especially undergoing $\mathrm{pH}$ shifting from 1.2 to 6.8 . The IPC visually had insignificant slope prior the $\mathrm{pH}$ shifting and after shifting. Although the PM had a different result, the slope increased after the $\mathrm{pH}$ shifting. The $\mathrm{pH}$ shifting affected the solubility of the polymers, especially Eud L which was soluble at the $\mathrm{pH}$ above 6 (Patra et al., 2017; Thakral et al., 2013). Therefore, the $\mathrm{pH}$ shifting in the PM induced a burst release effect. It had been proved by increasing the $\mathrm{DE}_{6.8}$ and $\mathrm{DE}_{\text {total }}$ values significantly. However, the $f_{2}$ value more than 50 (58.27). The interaction between two polymers in the IPC system was mediated by a hydrogen bonding interaction, thus the mobility of polymer chain and permeability were reduced, as a consequence, the drug release retarded (Zhang et al., 2016a). In addition, in the non-IPC, the chain polymers depended on the characteristic of the
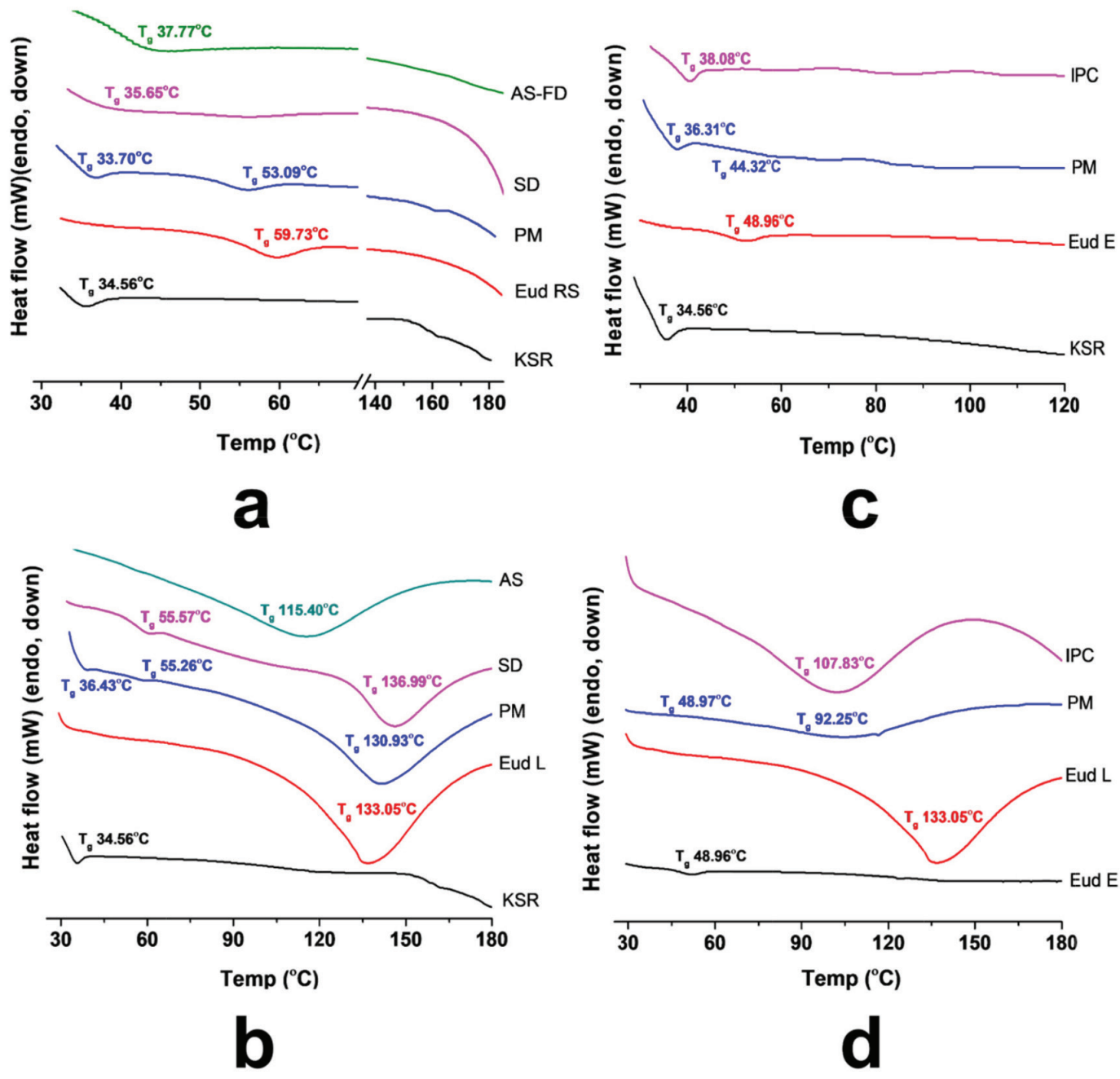

Figure 3. (a) FTIR Spectra of Eudragit RS (Eud RS)-Kollidon SR (KSR) inter-polymer complexes (IPCs); (b) differential spectra PM and Eud RS-KSR IPC; (c) Eud L-KSR IPC; and (d) differential spectra of PM and Eud L-KSR IPC. Physical mixture (PM) and inter-polymer complexes using spray drying (SD) and anti-solvent (AS) techniques. 
single polymer and both polymers did not interact. In the IPC, the SD process induced a curing effect of polymer and increased the crosslinked polymers. The phenomenon was enhanced the ability of polymer to control the drug release (Gendre et al., 2012).

The THP release of Eud E-KSR IPC and its PM are presented in Figure 4c. As aforementioned, the interaction of Eud $\mathrm{E}$ and KSR involved van der Waals interaction. This interaction was very weak, thus the THP release of IPC and PM did not significant difference and had a similar pattern and profiles $\left(f_{2}=\right.$ 62.95). However, it differed from the previous result in the Eud RS-KSR IPC, the PM in this system had more ability to retard the THP release compared to the IPC. Moreover, depending on the characterization results, the complex in both polymers did not occur completely and did not in the miscible system. It was confirmed by FTIR and thermal analysis. Thus, the THP release in the system was mainly controlled by KSR and the Eud E had a negligible effect on the THP release. The SD process altered

Table 1. Formula composition of IPC matrix-based tablet.

\begin{tabular}{lccccc}
\hline Polymers & $\begin{array}{c}\text { IPC } \\
\text { Preparation }\end{array}$ & $\begin{array}{c}\text { Theophylline } \\
(\mathbf{m g})\end{array}$ & $\begin{array}{c}\text { IPC } \\
(\mathbf{m g})\end{array}$ & $\begin{array}{c}\text { MgSt } \\
(\mathbf{m g})\end{array}$ & $\begin{array}{c}\text { Fumed } \\
\text { Silica (mg) }\end{array}$ \\
\hline Eud RS-KSR & SD & 200 & 196 & 3.2 & 0.8 \\
& AS-FD & 200 & 196 & 3.2 & 0.8 \\
Eud L-KSR & PM & 200 & 196 & 3.2 & 0.8 \\
& SD & 200 & 196 & 3.2 & 0.8 \\
& AS & 200 & 196 & 3.2 & 0.8 \\
Eud E-KSR & PM & 200 & 196 & 3.2 & 0.8 \\
& SD & 200 & 196 & 3.2 & 0.8 \\
Eud E-Eud L & PM & 200 & 196 & 3.2 & 0.8 \\
& SE & 200 & 196 & 3.2 & 0.8 \\
& PM & 200 & 196 & 3.2 & 0.8 \\
\hline
\end{tabular}

SD, Spray drying; AS-FD, anti-solvent-freeze drying; PM, physical mixture; AS, antisolvent; SE, solvent evaporation; IPC, interpolymer complex; MgSt, magnesium stearate; Eud, Eudragit; KSR, Kollidon SR.

Table 2. Predicted and observed the glass transition temperature $\left(T_{\mathrm{g}}\right)$ of Eudragit (Eud) RS/L/E, Kollidon SR (KSR), and their IPCs.

\begin{tabular}{|c|c|c|c|c|}
\hline \multirow{2}{*}{ Polymers/IPCs } & \multirow{2}{*}{$\begin{array}{l}\text { Reported } T_{\mathrm{g}} \\
\quad\left({ }^{\circ} \mathrm{C}\right)\end{array}$} & \multirow{2}{*}{$\begin{array}{l}\text { Predicted } T_{\mathrm{g}} \\
\quad\left({ }^{\circ} \mathrm{C}\right)\end{array}$} & \multicolumn{2}{|c|}{ Observed } \\
\hline & & & $T_{\mathrm{g}}\left({ }^{\circ} \mathrm{C}\right)$ & $\Delta \mathrm{Cp}(\mathrm{mW})$ \\
\hline Eud RS & $61.05^{\mathrm{a}} ; 63.02^{\mathrm{b}}$ & - & 59.73 & -0.21 \\
\hline Eud L & $123.15^{\mathrm{c}} ; 124.4^{\mathrm{d}}$ & - & 133.05 & -0.45 \\
\hline Eud E & $52.1^{\mathrm{d}}$ & - & 48.96 & -0.09 \\
\hline KSR & $42.54^{\mathrm{e}}$ & - & $34.56^{\mathrm{f}}$ & -0.33 \\
\hline Eud RS-KSR SD & - & 44.35 & 184.28 & -1.70 \\
\hline Eud RS-KSR AS & - & 44.35 & 37.77 & -1.52 \\
\hline Eud L-KSR SD & - & 91.38 & $55.57 ; 136.99$ & $-0.37 ;-0.84$ \\
\hline Eud L-KSR AS & - & 91.38 & $115.40^{\mathrm{g}}$ & -1.10 \\
\hline Eud E-KSR SD & - & 37.65 & 38.08 & -0.28 \\
\hline Eud E-Eud L SE & - & 119.04 & $107.83^{\mathrm{g}}$ & -1.24 \\
\hline
\end{tabular}

a(Zhu et al., 2002)

b(Khodaverdi et al., 2012).

'(Lang et al., 2016).

d(Moustafine et al., 2006).

'(Saerens et al., 2012).

${ }^{\mathrm{f}}$ Measured at $60 \% \mathrm{RH}$.

${ }^{\mathrm{g}} \mathrm{A}$ broad endothermic peak due to curing effect. the physicochemical of the polymers to the amorphous system (Al-Zoubi et al., 2016), thus it altered the KSR physicochemical to control the THP release. Although, this system improved the physicomechanical property, i.e., compactibility (data not shown).

Different interactions in the IPC involved an electrolyte complex, such as in the Eud E and Eud L. Eud E as a polycationic polymer (polyamonio methacrylate) and Eud L as a polyanionic polymer (polyacrylic acid), both interacted by an ionic interaction (Jeganathan and Prakya, 2015; Moustafine et al., 2006; Moustafine and Bobyleva, 2006). The interaction had a significant effect on the THP release effect. The THP releases of Eud E-Eud L IPC and its PM are presented in Figure 4d. The THP release of IPC showed that two-step burst release effect was observed in the $\mathrm{pH}$ shifting $\left(f_{2}=23.19\right)$. We assumed that the two-step burst release effect promoted by physicomechanical properties of the IPC and the IPC produced $\mathrm{pH}$-independent solubility. The IPC reduced the physicomechanical characteristic compared to the PM. As the previous report, the Eud E-Eud L IPC could be controlled the drug release of ibuprofen (poorly water-soluble drug) until 4 hours at pH 6.8 (Moustafine et al., 2006). However, different preparation methods in the formation of IPC altered the physicochemical or physicomechanical properties of the IPC. Therefore, different results from this study were affected by the different preparation methods. The IPC was produced under a precipitation in methanol followed by an evaporation of the solvent. In addition, we assumed that the interaction between IPC did not completely occurred and curing effect affected on the increasing of solubility and swelling ability of the IPC. Furthermore, the score plot of PCA of the THP release profiles was applied to distinguish the THP release pattern clearly and it is presented in Figure 5. Both of IPCs and PMs of Eud RS-KSR or Eud L-KSR THP releases had a similar pattern in $\mathrm{pH} 1.2$ in which it was assigned by closeness of score points in Figure 5a. Meanwhile, the THP release of PM Eud L-KSR had different pattern of THP release in the $\mathrm{pH} 6.8$ (Fig. 5b) and total THP release for 6 hours (Fig. 5c) and it proved that IPC enhanced to control the THP release. Thus, the IPC had similar ability to control the THP release compared to the Eud RS-KSR IPC or PM. Nevertheless, the IPC Eud RS-KSR was suitable as a promising material to control the THP release, especially as a swellable polymer due to the swelling ability (data not shown). The others IPCs and PMs (Eud L-KSR, Eud E-KSR, and Eud E-Eud L) had dissimilar score plot pattern (i.e., THP release profiles) in term of THP release in the $\mathrm{pH} 1.2$ and 6.8 as well as total THP released.

In order to understand the THP release mechanism from the IPCs tablet, the THP release modeling was carried out using several models. The visual goodness of fit of IPCs or PMs is presented in Figure 6. All THP release profiles were modeled except the THP release of Eud E-Eud L IPC due to a two-step burst release profiles. Based on the prior experimental, there was no proper model to describe the THP release kinetics. Although, a separated THP release profile depending on the $\mathrm{pH}$ release could be modeled separately. All the purposed models had a significant term $(p<0.05)$. To evaluate the appropriate model goodness of fit (GoF), both visual and statistical approaches were evaluated. Statistical parameter of modeling is presented in Table 3. For the conventional, drug release profile was suitable to be modeled using Higuchi, first-order kinetic, or Korsmeyer-Peppas models. The drug release profile which had burst release effect model was suitable to be modeled using either 
polynomial or double exponential models. These models were a simplified equation of Fick diffusion model (Costa and Sousa Lobo, 2001; Siepmann and Siepmann, 2012). Based on the visual GoF, the best model was depicted by the observed value close to the predicted line. The statistical GoF was depended on the $R^{2}$, adjusted $R^{2}$, and predicted residual error sum square (PRESS). The higher $R^{2}$ and adj. $R^{2}$ and the lower PRESS, the better model selection parameters (Ainurofiq and Choiri, 2018). Either polynomial or double exponential models were the best models to describe the drug release kinetics due to the highest $R^{2}$ and adjusted $R^{2}$ and the lowest PRESS. The THP release which had a burst release effect during the pH shifting, e.g., Eud L-KSR IPC was suitable to be modeled using quadratic model and the other THP release was suitable to be modeled using double exponential equation using four parameters. This model explained the THP release constant as a non-linear function. The first exponential model described the drug release after the swelling formation, and the second exponential model described the drug release in the first time, especially presence of the initial burst release effect due to the high drug loading and drug solubility. The rate of polymer swelling and the drug solubility determined the initial burst release effect. The faster rate of polymer swelling, the lower initial burst release effect is. Moreover, the higher solubility and drug load, the greater burst release effect is (Huang and Brazel, 2001). Depending on the diffusional exponent of Korsmeyer-Peppas equation and the characteristic of native polymer, the drug release from IPCs was mainly controlled by a diffusion mechanism. The drug characteristics, e.g., solubility, molecular weight and matrix interaction, and polymer permeability as key factors determined on the drug release mechanism by diffusion. The observation confirmed that there was no erosion or leakage of the matrix during the drug release testing and the dosage form maintained its geometric integrity during the test.
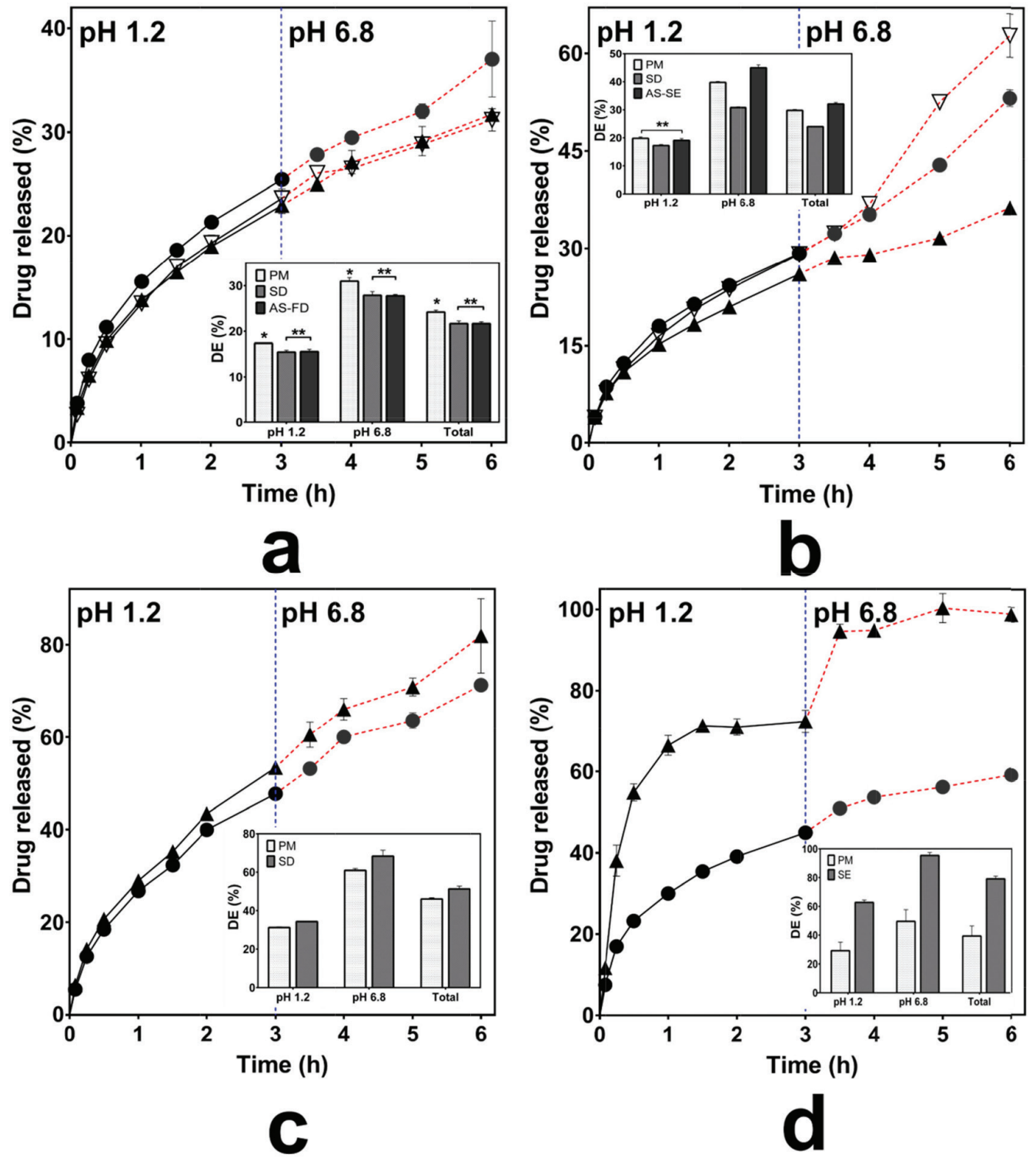

Figure 4. Drug release profiles of (a) Kollidon SR (KSR)-Eudragit (Eud) RS, (b) KSR-Eud L, (c) KSR-Eud E, and Eud E-Eud L inter-polymer complexes using spray drying (solvent evaporation for Eud E-Eud L) $(\boldsymbol{\Delta})$ and anti-solvent $(\nabla)$ and their physical mixturees $(\bullet)$. DE $=$ dissolution efficiency, $*=p<0.05$, and $* *=p>0.05$. 


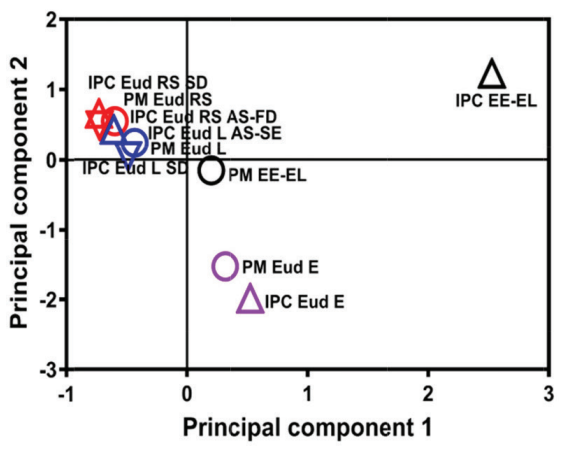

a

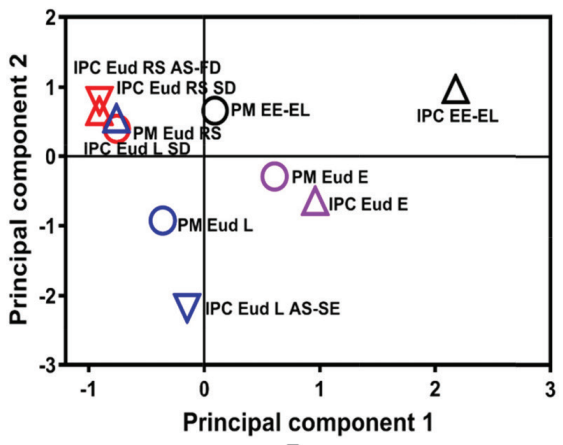

b

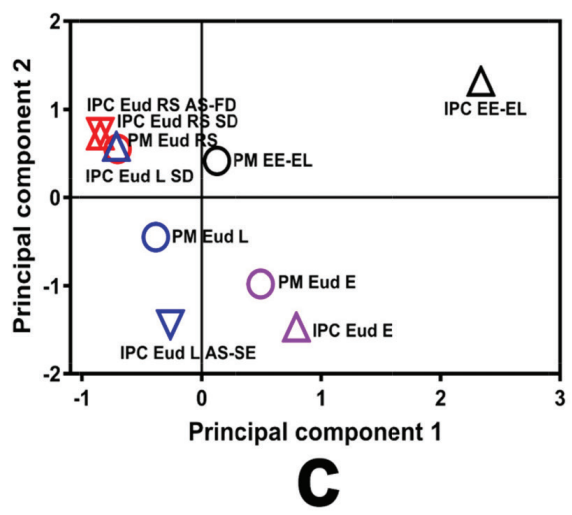

Figure 5. Score plot of principal component analysis of the drug release profiles at (a) $\mathrm{pH} 1.2$, (b) $\mathrm{pH} 6.8$, and (c) total drug released.

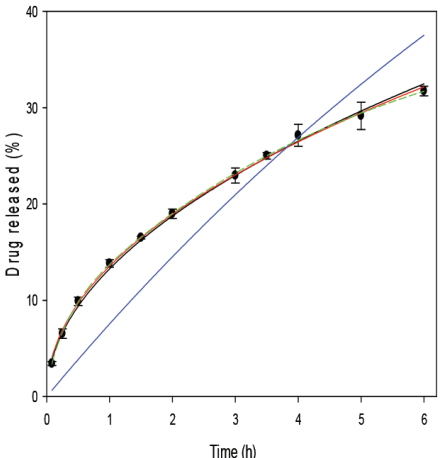

a

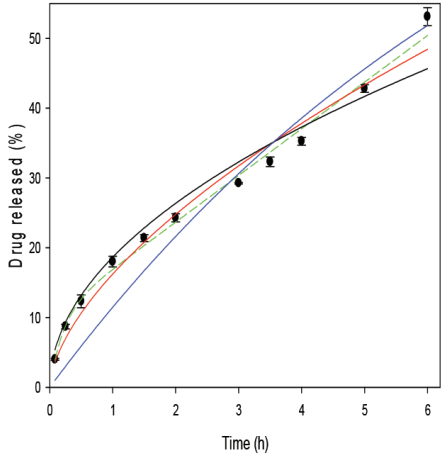

e

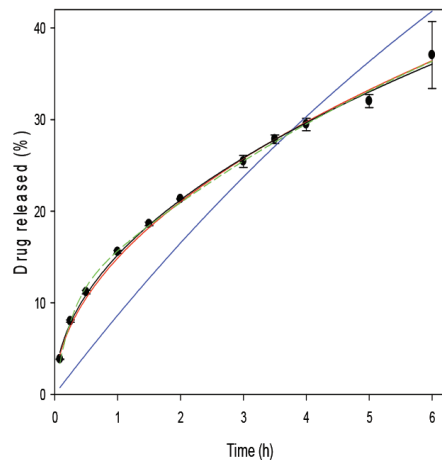

b

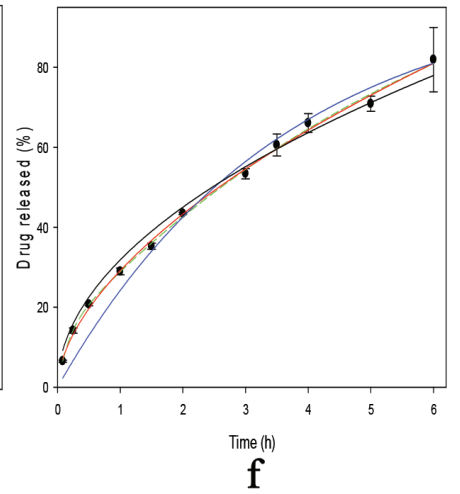

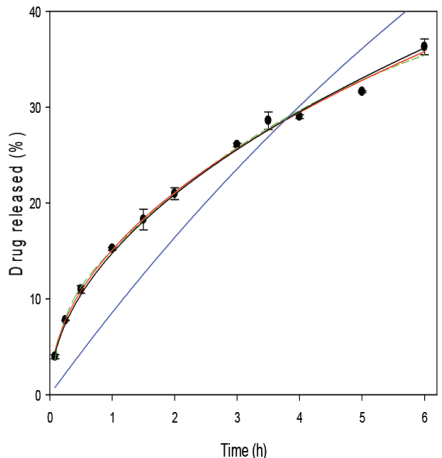

C

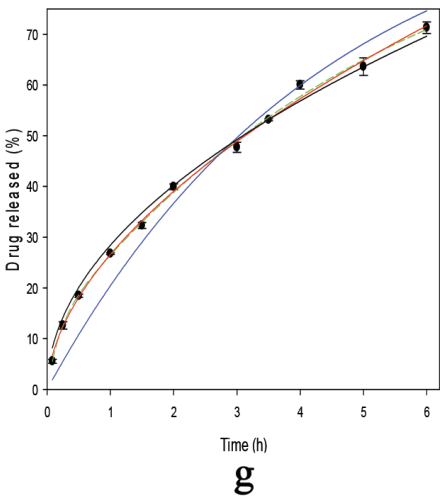

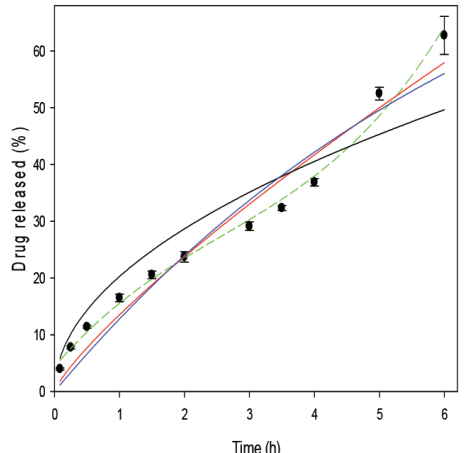

d

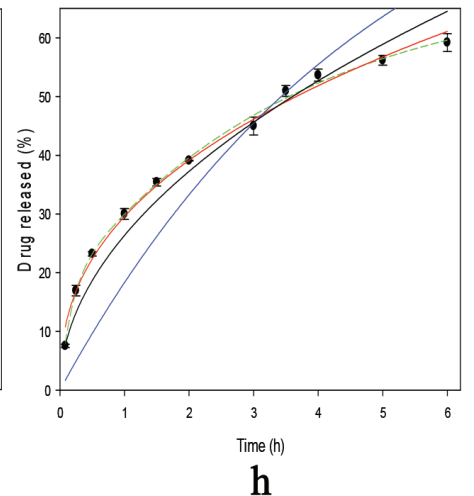

Figure 6. Modeling the drug release of (a) Inter-polymer complex (IPC) of Eudragit (Eud) RS-Kollidon SR (KSR), (b) Eud RS-KSR physical mixture (PM), (c) Eud L-KSR IPC using spray drying (SD) technique, (d) Eud L-KSR IPC using anti-solvent technique, (e) Eud L-KSR PM, (f) Eud E-KSR IPC SD, (g) Eud E-KSR PM, and (h) Eud E-Eud L PM. Higuchi model (straight black line), First-order kinetics (straight blue line), Korsmeyer-Peppas model (straight red line), and either polynomial or quadratic models (dashed green line). 
Table 3. Statistical parameters of modeling of drug release kinetics.

\begin{tabular}{|c|c|c|c|c|c|c|c|c|c|}
\hline \multirow{2}{*}{ Model } & \multirow{2}{*}{$\begin{array}{l}\text { Statistical } \\
\text { Parameters }\end{array}$} & \multicolumn{2}{|c|}{ Eud RS-KSR } & \multicolumn{3}{|c|}{ Eud L-KSR } & \multicolumn{2}{|c|}{ Eud E-KSR } & \multirow{2}{*}{$\frac{\text { Eud L-Eud E }}{\text { PM }}$} \\
\hline & & PM & IPC & PM & IPC SD & IPC AS & PM & IPC & \\
\hline \multirow[t]{4}{*}{ Higuchi } & $R^{2}$ & 0.9877 & 0.9939 & 0.9594 & 0.9942 & 0.8849 & 0.9914 & 0.9806 & 0.9633 \\
\hline & Adj. $R^{2}$ & 0.9877 & 0.9939 & 0.9594 & 0.9942 & 0.8849 & 0.9914 & 0.9806 & 0.9633 \\
\hline & PRESS & 47.32 & 18.20 & 305.00 & 21.09 & 1305.6 & 132.36 & 400.23 & 238.32 \\
\hline & $k_{H}$ & 14.87 & 13.26 & 18.64 & 14.76 & 20.27 & 28.42 & 31.83 & 26.34 \\
\hline \multirow[t]{4}{*}{ First order } & $R^{2}$ & 0.7764 & 0.7703 & 0.9161 & 0.7794 & 0.9368 & 0.9528 & 0.9604 & 0.7226 \\
\hline & Adj. $R^{2}$ & 0.7764 & 0.7703 & 0.9161 & 0.7794 & 0.9368 & 0.9528 & 0.9604 & 0.7226 \\
\hline & PRESS & 789.36 & 653.74 & 573.91 & 765.32 & 697.53 & 703.38 & 766.51 & 1716.6 \\
\hline & $k_{1}$ & 0.09 & 0.08 & 0.12 & 0.09 & 0.14 & 0.23 & 0.28 & 0.20 \\
\hline \multirow[t]{7}{*}{ Exponential or polynomial } & $R^{2}$ & 0.9978 & 0.9954 & 0.9907 & 0.9947 & 0.9989 & 0.9967 & 0.9889 & 0.9959 \\
\hline & Adj. $\mathrm{R}^{2}$ & 0.9974 & 0.9949 & 0.9897 & 0.9942 & 0.9878 & 0.9963 & 0.9877 & 0.9952 \\
\hline & PRESS & 6.79 & 15.51 & 92.58 & 22.94 & 166.67 & 59.07 & 322.49 & 34.74 \\
\hline & $A$ & 8.04 & 7.06 & 10.29 & 7.93 & 13.45 & 11.81 & 13.00 & 17.42 \\
\hline & $B$ & 5.50 & 5.00 & 4.66 & 5.64 & -2.64 & 5.24 & 5.91 & 5.72 \\
\hline & $C$ & 35.62 & 33.66 & $6.9 \times 10^{6}$ & 38.93 & 0.34 & 89.83 & 144.70 & 52.04 \\
\hline & $D$ & 0.23 & 0.22 & $9.6 \times 10^{-6}$ & 0.20 & $\mathrm{y}_{0} 4.39$ & 0.18 & 0.15 & 0.28 \\
\hline \multirow[t]{5}{*}{ Korsmeyer-Peppas } & $R^{2}$ & 0.9883 & 0.9945 & 0.9754 & 0.9949 & 0.9570 & 0.9961 & 0.9884 & 0.9901 \\
\hline & Adj. $R^{2}$ & 0.9980 & 0.9943 & 0.9746 & 0.9948 & 0.9556 & 0.9960 & 0.9880 & 0.9896 \\
\hline & PRESS & 50.15 & 17.04 & 199.53 & 19.29 & 513.29 & 63.32 & 274.68 & 70.61 \\
\hline & $K$ & 15.20 & 13.54 & 16.23 & 15.11 & 13.53 & 26.60 & 29.15 & 29.54 \\
\hline & $N$ & 0.482 & 0.483 & 0.610 & 0.481 & 0.811 & 0.553 & 0.571 & 0.406 \\
\hline
\end{tabular}

\section{CONCLUSION}

IPCs between Eud types and KSR had been characterized. ATR-FTIR and thermal analysis confirmed the interaction of IPCs. The Eud RS-KSR and Eud E-KSR had a similar interaction through a van der Waals interaction. Although, these had different effects on the THP release due to native characteristics of the polymers. Eud L-KSR which had a hydrogen bonding interaction and curing effect failed to control the THP release after $\mathrm{pH}$ shifting. The Eud E-Eud L IPC showed two-step burst release effect due to the solubility alteration of the polymers. It could be concluded that either positive or negative effect in the IPC could be observed depending on the native characteristics of the polymers and their interactions.

\section{ACKNOWLEDGMENT}

This research was funded by Indonesian Endowment Fund for Education (LPDP). The authors would like to thank Evonik (Darmstadt, Germany) for providing Eudragit polymers, and BASF (Ludwigshafen, Germany) for providing Kollidon SR.

\section{CONFLICT OF INTEREST}

All authors (Choiri S., T.N.S. Sulaiman, and A. Rohman) declare that they have no conflict of interest.

\section{REFERENCES}

Ainurofiq A, Choiri S. Development and optimization of a meloxicam/ $\beta$-cyclodextrin complex for orally disintegrating tablet using statistical analysis. Pharm Dev Technol, 2018; 23:464-75; dx.doi.org/10.10 80/10837450.2016.1264418

Ainurofiq A, Choiri S. Drug release model and kinetics of natural polymers-based sustained release tablet. Lat Am J Pharm, 2015; 34:1328-37.

Ali R, Dashevsky A, Bodmeier R. Poly vinyl acetate and ammonio methacrylate copolymer as unconventional polymer blends increase the mechanical robustness of HPMC matrix tablets. Int J Pharm, 2017; 516:3-8; dx.doi.org/10.1016/j.ijpharm.2016.10.069

Al-Zoubi N, Al-obaidi G, Tashtoush B, Malamataris S. Sustained release of diltiazem $\mathrm{HCl}$ tableted after co-spray drying and physical mixing with PVAc and PVP. Drug Dev Ind Pharm, 2016; 42:270-9; dx.doi.org/10. 3109/03639045.2015.1047848

Borgquist P, Körner A, Piculell L, Larsson A, Axelsson A. A model for the drug release from a polymer matrix tablet - effects of swelling and dissolution. J Control Release, 2006; 113:216-25; dx.doi.org/10.1016/j. jconrel.2006.05.004

Brostow W, Chiu R, Kalogeras IM, Vassilikou-Dova A. Prediction of glass transition temperatures: binary blends and copolymers. Mater Lett, 2008; 62:3152-5; dx.doi.org/10.1016/j.matlet.2008.02.008

Costa P, Sousa Lobo JM. Modeling and comparison of dissolution profiles. Eur J Pharm Sci, 2001; 13:123-33; dx.doi.org/10.1016/ S0928-0987(01)00095-1

Elzayat EM, Abdel-Rahman AA, Ahmed SM, Alanazi FK, Habib WA, Sakr A. Multiple response optimization of processing and formulation parameters of Eudragit RL/RS-based matrix tablets for sustained delivery of diclofenac. Pharm Dev Technol, 2017; 22:928-38; dx.doi.org/10.1080/1 0837450.2016.1212880

Gendre C, Genty M, Silva JC da, Tfayli A, Boiret M, Lecoq $\mathrm{O}$, et al. Comprehensive study of dynamic curing effect on tablet coating structure. Eur J Pharm Biopharm, 2012; 81:657-65; dx.doi.org/10.1016/j. ejpb.2012.04.006

Gordon M, Taylor JS. Ideal copolymers and the second-order transitions of synthetic rubbers. i. non-crystalline copolymers. J Appl Chem, 1952; 2:493-500; dx.doi.org/10.1002/jctb.5010020901

Hauschild K, Picker-Freyer KM. Evaluation of tableting and tablet properties of Kollidon SR: the influence of moisture and mixtures with theophylline monohydrate. Pharm Dev Technol, 2006; 11:125-40; dx.doi.org/10.1080/10837450500464289

Hayashi T, Kanbe H, Okada M, Suzuki M, Ikeda Y, Onuki Y, Kaneko T, Sonobe T. Formulation study and drug release mechanism of a new theophylline sustained-release preparation. Int J Pharm, 2005; 304:91101; dx.doi.org/10.1016/j.ijpharm.2005.07.022 
Hong Y, Liu G, Gu Z. Recent advances of starch-based excipients used in extended-release tablets: a review. Drug Deliv, 2016; 23:12-20; dx.doi.org/10.3109/10717544.2014.913324

Huang X, Brazel CS. On the importance and mechanisms of burst release in matrix-controlled drug delivery systems. J Control Release Off J Control Release Soc, 2001; 73:121-36.

Jeganathan B, Prakya V. Interpolyelectrolyte complexes of Eudragit ${ }^{\circledR}$ EPO with hypromellose acetate succinate and Eudragit ${ }^{\circledR}$ EPO with hypromellose phthalate as potential carriers for oral controlled drug delivery. AAPS PharmSciTech, 2015; 16:878-88; dx.doi.org/10.1208/s12249-014$0252-2$

Khodaverdi E, Tekie FSM, Amoli SS, Sadeghi F. Comparison of plasticizer effect on thermo-responsive properties of Eudragit RS films. AAPS PharmSciTech, 2012; 13:1024-30; dx.doi.org/10.1208/s12249-0129827-y

Khutoryanskaya OV, Morrison PWJ, Seilkhanov SK, Mussin MN, Ozhmukhametova EK, Rakhypbekov TK, Khutoryanskiy VV. Hydrogen-bonded complexes and blends of poly(acrylic acid) and methylcellulose: nanoparticles and mucoadhesive films for ocular delivery of riboflavin. Macromol Biosci, 2014; 14:225-34; dx.doi.org/10.1002/ mabi.201300313

Khutoryanskiy VV. Hydrogen-bonded interpolymer complexes as materials for pharmaceutical applications. Int J Pharm, 2007; 334:15-26; dx.doi.org/10.1016/j.ijpharm.2007.01.037

Kubova K, Peček D, Hasserová K, Doležel P, Pavelková M, Vyslouzil J, Muselík J, Vetchy D. The influence of thermal treatment and type of insoluble poly(meth)acrylates on dissolution behavior of very soluble drug from hypromellose matrix tablets evaluated by multivariate data analysis. Pharm Dev Technol, 2017; 22:206-17; dx.doi.org/10.1080/1 0837450.2016 .1193191

Lang B, Liu S, McGinity JW, III ROW. Effect of hydrophilic additives on the dissolution and pharmacokinetic properties of itraconazoleenteric polymer hot-melt extruded amorphous solid dispersions. Drug Dev Ind Pharm, 2016; 42:429-45; dx.doi.org/10.3109/03639045.2015.1075031

Liechty WB, Kryscio DR, Slaughter BV, Peppas NA. Polymers for Drug Delivery Systems. Annu Rev Chem Biomol Eng, 2010; 1:149-73; dx.doi.org/10.1146/annurev-chembioeng-073009-100847

Makino S, Adachi M, Ohta K, Kihara N, Nakajima S, Nishima S, Fukuda T, Miyamoto T; Safety of Sustained-Release Theophylline and Injectable Methylxanthines Committee; Asthma Prevention and Management Guidelines Committee. A prospective survey on safety of sustained-release theophylline in treatment of asthma and COPD. Allergol Int, 2006; 55:395-402; dx.doi.org/10.2332/allergolint.55.395

Masina N, Choonara YE, Kumar P, du Toit LC, Govender M, Indermun S, Pillay V. A review of the chemical modification techniques of starch. Carbohydr Polym, 2017; 157:1226-36; dx.doi.org/10.1016/j. carbpol.2016.09.094

Merkle HP. Drug delivery's quest for polymers: where are the frontiers? Eur J Pharm Biopharm, 2015; 97:293-303; dx.doi.org/10.1016/j. ejpb.2015.04.038

Moustafine RI, Bobyleva OV. Design of new polymer carriers based of Eudragit $\AA$ E PO/Eudragit $\AA$ L100-55 interpolyelectrolyte complexes using swellability measurements. J Control Release, 2006; 116:e35-6; dx.doi.org/10.1016/j.jconrel.2006.09.036

Moustafine RI, Bodrov AV, Kemenova VA, Rombaut P, Van den Mooter G. Drug release modification by interpolymer interaction between countercharged types of Eudragit ${ }^{\circledR}$ RL 30D and FS 30D in double-layer films. Int J Pharm, 2012; 439:17-21; dx.doi.org/10.1016/j. ijpharm.2012.09.044

Moustafine RI, Zaharov IM, Kemenova VA. Physicochemical characterization and drug release properties of Eudragit ${ }^{\circledR}$ E PO/Eudragit $\AA$ L 100-55 interpolyelectrolyte complexes. Eur J Pharm Biopharm, 2006; 63:26-36; dx.doi.org/10.1016/j.ejpb.2005.10.005

Mustafin RI. Interpolymer combinations of chemically complementary grades of Eudragit copolymers: a new direction in the design of peroral solid dosage forms of drug delivery systems with controlled release (review). Pharm Chem J, 2011; 45:285; dx.doi.org/10.1007/s11094011-0618-7
Ohyagi N, Ueda K, Higashi K, Yamamoto K, Kawakami K, Moribe K. Synergetic role of hypromellose and methacrylic acid copolymer in the dissolution improvement of amorphous solid dispersions. J Pharm Sci, 2017; 106:1042-50; dx.doi.org/10.1016/j.xphs.2016.12.005

Park S-H, Chun M-K, Choi H-K. Preparation of an extendedrelease matrix tablet using chitosan/Carbopol interpolymer complex. Int J Pharm, 2008; 347:39-44; dx.doi.org/10.1016/j.ijpharm.2007.06.024

Patra ChN, Priya R, Swain S, Kumar Jena G, Panigrahi KC, Ghose D. Pharmaceutical significance of Eudragit: a review. Future J Pharm Sci, 2017; 3:33-45; dx.doi.org/10.1016/j.fjps.2017.02.001

Qiu Y, Lee PI. Rational design of oral modified-release drug delivery systems. Dev. Solid Oral Dos. Forms 2nd edition, Academic Press, Boston, MA, pp 519-54, 2017; dx.doi.org/10.1016/B978-0-12-8024478.00019-4

Riaz U, Ashraf SM. Characterization of polymer blends with FTIR spectroscopy. In: Thomas S, Grohens Y, Jyotishkumar P (eds.). Charact. Polym. Blends, Wiley-VCH Verlag GmbH \& Co. KGaA, Weinheim, Germany, pp 625-78, 2014; dx.doi.org/10.1002/9783527645602.ch20

Robertis SD, Bonferoni MC, Elviri L, Sandri G, Caramella C, Bettini R. Advances in oral controlled drug delivery: the role of drugpolymer and interpolymer non-covalent interactions. Expert Opin Drug Deliv, 2015; 12:441-53; dx.doi.org/10.1517/17425247.2015.966685

Saerens L, Dierickx L, Quinten T, Adriaensens P, Carleer $\mathrm{vR}$, Vervaet C, Remon JP, De Beer T. In-line NIR spectroscopy for the understanding of polymer-drug interaction during pharmaceutical hot-melt extrusion. Eur J Pharm Biopharm, 2012; 81:230-7; dx.doi.org/10.1016/j. ejpb.2012.01.001

Siepmann J, Siepmann F. Modeling of diffusion controlled drug delivery. J Control Release, 2012; 161:351-62; dx.doi.org/10.1016/j. jconrel.2011.10.006

Terashima T, Sugita T, Sawamoto M. Single-chain crosslinked star polymers via intramolecular crosslinking of self-folding amphiphilic copolymers in water. Polym J, 2015; 47:667-77; dx.doi.org/10.1038/ pj.2015.54

Thakral S, Thakral NK, Majumdar DK. Eudragit $($ : a technology evaluation. Expert Opin Drug Deliv, 2013; 10:131-49; dx.doi.org/10.1517 /17425247.2013.736962

Wood LA. Glass transition temperatures of copolymers. J Polym Sci, 1958; 28:319-30; dx.doi.org/10.1002/pol.1958.1202811707

Zayed M, Tourne-Peteilh C, Ramonda M, Rethore G, Weiss P, Martinez J, Subra G, Mehdi A, Devoisselle JM, Legrand P. Microgels of silylated HPMC as a multimodal system for drug co-encapsulation. Int J Pharm, 2017; 532:790-801; dx.doi.org/10.1016/j.ijpharm.2017.07.074

Zhang F, Lubach J, Na W, Momin S. Interpolymer complexation between Polyox and Carbopol, and its effect on drug release from matrix tablets. J Pharm Sci, 2016a; 105:2386-96; dx.doi.org/10.1016/j. xphs.2016.05.020

Zhang F, Meng F, Lubach J, Koleng J, Watson NA. Properties and mechanisms of drug release from matrix tablets containing poly(ethylene oxide) and poly(acrylic acid) as release retardants. Eur J Pharm Biopharm, 2016b; 105:97-105; dx.doi.org/10.1016/j.ejpb.2016.05.024

Zhang F, Meng F, Wang ZY, NA W. Interpolymer complexation between copovidone and carbopol and its effect on drug release from matrix tablets. Drug Dev Ind Pharm, 2017; 43:190-203; dx.doi.org/10.1080/0363 9045.2016.1230625

Zhu Y, Shah NH, Malick AW, Infeld MH, McGinity JW. Solidstate plasticization of an acrylic polymer with chlorpheniramine maleate and triethyl citrate. Int J Pharm, 2002; 241:301-10; dx.doi.org/10.1016/ S0378-5173(02)00244-2

How to cite this article:

Choiri S, Sulaiman TNS, Rohman A. Characterization of Eudragit types and Kollidon SR inter-polymer complexes and their effects on the drug release. J Appl Pharm Sci, 2019; 9(07):058-068. 